\title{
MUNDO LABORAL E COVID-19: CONSEQUÊNCIAS E POSSIBILIDADES PARA A SAÚDE MENTAL
}

\section{ARTIGO ORIGINAL}

OLIVEIRA, José Fernando Lima de ${ }^{1}$

OLIVEIRA, José Fernando Lima de. Mundo laboral e COVID-19: Consequências e possibilidades para a saúde mental. Revista Científica Multidisciplinar Núcleo do Conhecimento. Ano 05, Ed. 10, Vol. 04, pp. 121-128. Outubro de 2020. ISSN: 24480959, Link de acesso:https://www.nucleodoconhecimento.com.br/saude/mundolaboral

\section{RESUMO}

Diante do cenário atual de pandemia, observamos não só os registros sanitários sendo atualizados constantemente, mas o desaceleramento da economia causada pelo fechamento de diversos serviços, distanciamento social e enclausuramento ao redor do mundo. Por consequência disso, áreas de convivência, comércios, eventos esportivos ou outros espaços de aglomerações de pessoas se tornaram terras desoladas. Empresas fechando portas e outras recebendo socorro público para não quebrarem. Os números de desemprego tem crescido em todo mundo. A contragosto, muitos têm voltado para casa. O cenário posto se desenha como uma problemática para a saúde mental. Objetivo: o objetivo deste estudo consistiu discutir a questão da saúde mental ante as consequências da nova pandemia de COVID-19 no mundo do trabalho. Pergunta problema: como a questão da pandemia afeta a questão da saúde mental. Metodologia: como metodologia, realizamos uma revisão bibliográfica de artigos e estatísticas atuais de estudos pesquisados no google acadêmico e matérias, no sentido de ter, tanto quanto possível números recentes sobre o problema.

1 Mestrando em educação pela UDE; pós-graduado em saúde mental pela Universidade Católica Dom Bosco (2014); e graduado em psicologia pela Universidade Potiguar (2011). 
Principais resultados: como resultados esperados, acreditamos ter prestado a colaboração e atenção a temática, pavimentado a estrada para possíveis ações que serão requeridas num futuro vindouro.

Palavras chave: saúde mental, pandemia, trabalho.

\section{INTRODUÇÃO}

A história remonta momentos pelos quais a humanidade passou intensas crises, sejam elas por meio das guerras, pela economia, conflitos, catástrofes ou mesmo pandemias. O momento atual, certamente, terá registros históricos no futuro como um período em que o mundo parou, face às consequências de uma doença que se alastrou em escala global, afetando quase que instantaneamente todo o mundo. A rapidez e facilidade da transmissão do novo COVID-19 viaja numa assombrosa progressão geométrica, deste modo não era de se esperar que medidas pró saúde fossem dadas pelas autoridades de seus respectivos países, no sentido de evitar, tanto quanto possível, que um infectado assintomático pudesse transmitir o vírus a outras pessoas. Entre as medidas adotadas pelas autoridades de saúde dos países, estão o uso de máscaras para atividades no dia a dia; uso de álcool para higienização pessoal; e, principalmente, o isolamento social. Esta última, como de consenso entre especialistas em infectologia, é a estratégia mais eficaz para evitar o aclive da curva nos números desta pandemia.

Diante desta pandemia, governos de todo mundo passaram a adotar o isolamento 0 social não mais como uma orientação e sim como uma imposição, cujo reflexo tem reverberado na economia mundial. Durante este período, apenas serviços considerados essenciais tem funcionado, assim qualquer outro ramo de negócio que não se enquadre dentro deste crivo não tem autorização para funcionamento, sendo até impostas pesadas sanções aos descumprintes. Assim, muitas empresas têm tentado driblar estes problemas com expedientes em home office, todavia isto tem respondido pelo baixo efetivo, em função das características do serviço, baixa aparelhagem e pronta necessidade de subsídios. Do outro lado, a triste realidade de 
muitos tem sido as demissões em massa, empresas fechando as portas ou no mínimo redução da jornadas de horas.

O que antes era garantia do certo para subsistência, hoje passa pela incerteza e a precarização das condições de vida sem recursos e a imprecisão de quanto tempo tudo isso irá perdurar. Diante desta situação, podemos estar às portas de um aumento expressivo do número de acometidos por transtornos mentais em todo mundo em face do rompimento abrupto do considerado básico para uma vida digna.

Acredita-se que as grandes questões que estão sendo levantadas neste instante talvez não sejam como ou quando toda essa pandemia irá passar, mas como iremos "juntar os cacos" após tudo isso. Grandes pandemias já afligiram o mundo em variadas épocas e o resultados delas nos mostra que talvez haja ainda meios para reerguer o mundo pós-pandêmico. O provável prognóstico aponta que a adoção de protocolos básicos e as estratégias de se constituir saúde no mundo, assim como as epidemias, também atravessaram fronteiras e desenvolverão novas práticas de conhecimento em prol da humanidade, obrigando as nações a uma maior valorização da saúde.

\section{DESENVOLVIMENTO}

\subsection{GRANDES PANDEMIAS}

Nos registros históricos de todo o mundo, variadas foram as situações de doenças que alcançaram escala global, constituindo-se em pandemias. Essas pandemias já causaram mais estragos que quaisquer terremotos, maremotos, guerras ou vulcões. Até a produção deste estudo, o site estado de minas internacional apontava que o novo COVID-19 já teria infectado mais de 4.647.980 pessoas em mais de 196 países, tendo vitimado fatalmente mais de 312 mil.

Embora notório, o grande impacto no mundo do novo COVID-19, não foi a única doença a atingir escala global. Outras doenças registraram elevados números de casos em todo mundo, deixando também um rastro de lutos por onde passaram. A peste bubônica, causada por uma bactéria, se espalhava pelo interação com pulgas 
e roedores infectados. Sintomas comuns a gripe e inchaço em várias partes do corpo eram frequentes. Esta teria também causado a peste negra, que assolou a Europa $e$ Ásia, vitimando fatalmente cerca de $25 \%$ da população mundial. A Varíola, doença que afligiu a humanidade e em 1980 foi considerada erradicada em função de amplo esquema de vacinação, todavia países como Rússia ainda se conserva amostras em laboratório. Cólera, inicialmente em 1817, matou centenas de milhares de pessoas que em razão de múltiplas mutações, de tempos em tempos, mostram registros significativos. Em 1918 eclodiu a gripe espanhola, na qual crê-se que tenha ocorrido cerca de 45 milhões de óbitos registrados e por volta de um quarto do mundo teria sido infectado nesta pandemia. Mais recentemente, a gripe suína vitimou fatalmente cerca de 16 mil pessoas em todo mundo (OMS, 2010).

Vale destacar que os registros históricos das doenças relatadas acima, foram responsáveis pela cultura da imunização no Brasil. Por outro prisma, a gripe asiática popularizou o uso de máscaras; a peste negra, a prática da quarentena; a gripe suína, aumentou a colaboração internacional no combate das doenças; e o HIV, estimulou o uso de preservativos. Desse modo, essas pandemias trouxeram significativas mudanças no mundo, assim como o legado que a peste negra deixou, com a implementação do regime de quarentena que forçou o fim do regime de servidão que estava em voga entre os camponeses, influenciando inclusive a economia de até então. Ou seja, os períodos de pandemia ensejaram transformações na maneira de vida das pessoas. Para tanto, quais as consequências que podemos ter no póspandemia do COVID-19?

\subsection{CONSEQUÊNCIAS PÓS PANDÊMICAS DO COVID-19 E A SAÚDE MENTAL}

O atual estado de paralisação das atividades e colapso total dos sistemas de saúde, tem basicamente a crise econômica como causadora e este, por sua vez, tem a pandemia como vilã. Em outras palavras, a crise econômica se originou de um desequilíbrio entre o consumo e a produção, cuja parada forçosa de atividades de trabalho tem causado o enfraquecimento da economia, não permitindo a circulação 
do capital, assim não fosse o funcionamento dos serviços, ditos essenciais, entraríamos em colapso total. Entretanto, a crise econômica tem produzido, irrefreadamente, a cada dia, novas vítimas, com empresas fechando as portas e empregados perdendo empregos. A onda de desemprego causada por esta pandemia acaba por ser o empurrão, ladeira a baixo, que a economia mundial precisava para recordar de grandes crises financeiras como a grande depressão de 1930, cujo reflexo causou cerca de $30 \%$ de desemprego em todo mundo, e mais recentemente, a avalanche de calotes imobiliários nos EUA. Em suma, podemos aferir que vivemos em tempos difíceis.

Diante desta problemática, algumas empresas têm sido muito inventivas, explorando formas antes nunca implementadas, mudando as atividades laborais ${ }^{[3]}$ de in loco para home office. Neste sentido, os empregados respeitam a quarentena, mas não deixam as engrenagens funcionais pararem, exercendo suas atividades em casa. Destarte, os recursos da tecnologia se configuraram como pontes, permitindo que em qualquer lugar haja trabalho. Reconhece-se que a tecnologia faz parte integrante do nosso dia a tal ponto de ser difícil de desagregar um do outro. Hoje no Brasil, o ministério da educação e as secretarias estaduais liberaram portarias emergenciais que autorizam o ensino básico e superior remoto e a assim os prejuízos acadêmicos aos alunos são, ainda que minimamente, recompensados. Os professores têm ministrado suas aulas em formato EaD. Sem embargo, os trabalhos remotos, por meio de home office, respondem por uma parcela ainda pequena e muitos são os desempregados. Ainda que os governos tenham entrado neste fronte de batalha, as baixas nas estatísticas laborais são grandes. No Brasil o governo tem beneficiado a população com auxílio emergencial e as empresas com o BEM.

Torna-se um imperativo absoluto reconhecer que o trabalho exerce um efeito de proteção à saúde, tanto a física como mental. A condição de desemprego, somado a impossibilidade de se buscar recolocação profissional, agravam a situação de saúde. A vulnerabilidade psíquica, fruto desta condição, é responsável por variados riscos. Para se compreender, a prevalência de depressão em inativos supera, e muito, aos 
empregados, e as estatísticas de suicídio sobem nos períodos de crise econômica. De acordo com Matos (2018, p.3):

Estudos psicossociais, evidenciam que o desemprego, não se restringe a fatores econômicos e sociais, trazendo consigo uma gama de implicações clínicas, que vão desde o comprometimento da autoestima, até casos mais extremos, relacionados a suicídio.

Nota-se com esta perspectiva que a situação de perda do emprego e, por conseguinte, desemprego pode alavancar problemas de saúde até então inexistentes. Silva e Lima (2017), enxergam no trabalho um alicerce fundamental, indispensável para a vida do homem. Por sua vez, Matos (2018, p.2) assinala que:

O trabalho, nos dias de hoje, é visivelmente valorizado em demasia pela política neoliberal das sociedades capitalistas. O ócio passou a ser considerado um pecado capital, e o trabalho, em contrapartida, passou a ser visto como um dever moral.

Por outro lado, o processo de precarização econômica e a era da comunicação nos tempos tecnológicos que vivemos, tem se apresentado como "uma faca de dois gumes", pois tem avultado o isolamento social e em períodos de quarentena torna-se ainda mais profunda a vulnerabilidade psíquica.

Pesquisas recentes, dão conta que a situação de perda do emprego tem efeitos ainda mais escusos para as pessoas e que são demasiadamente vivenciados como experiências dolorosas para a vida. Nestas pesquisas, o indivíduo sem ocupação, manifesta a perda da identidade e ausência no poder decisório sobre a própria vida, posto que a referida questão gera ainda um processo de parasitismo e dependência de outras pessoas, doravante provedores do lar, funcionando como um estorvo para os demais membros familiares, bem como apresentado, recentemente, no filme de 2019 "parasita”. (MATOS, 2008)

Conforme Matos (2018, p.6), estar sem emprego expõe o indivíduo a toda sorte de ataques psíquicos e até físicos, logo a pesquisadora assinala:

A falta de trabalho pode gerar uma vida sem significação e uma situação de vulnerabilidade social, a qual pode ocasionar uma desordem 
simbólica e psíquica. Estudos têm demonstrado que a situação de desemprego pode acarretar: conflitos no relacionamento familiar e social do sujeito; isolamento social; ocorrência constante de uso de álcool ou de outras drogas; apelo anormal para a religião ou esporte; ou agravamento de problemas sociais, como por exemplo, a criminalidade $[\ldots]$.

Para se compreender melhor o poço sem fundo ao qual o indivíduo desempregado é jogado, analisemos o contexto social do Japão. Lá não há difusão significativa do cristianismo, o que tornaria o suicídio uma prática pecaminosa e, portanto, se há menos amarras sociais para os indivíduos, somados ao "seppuku", uma prática suicida em nome da honra; e os períodos de crise econômica, elevam as taxas de suicídio a níveis alarmantes. Recentemente, a BBC noticiou um suicídio de um homem. Investigado, descobriu tratar-se de um indivíduo sozinho, desempregado, deprimido e que vivia no limite psicológico. Ainda neste contexto, na situação de um suicídio, os seguros de saúde pagam apólices logo após o ato e isto tem estimulado muitos que enxergam no suicídio a saída para os problemas financeiros da família, acreditando assim que é o melhor que pode fazer por eles. De acordo com Matos (2008, p.6):

A miséria imposta pela falta de perspectiva, arrebatando a esperança de concretizar o provimento da família e a desesperança de uma mudança a curto ou médio prazo deste quadro econômico, impulsiona várias pessoas a aceitarem sem pudor qualquer forma de atividade, uma vez que, entre o temor do desconhecido e a possibilidade de garantir a sobrevivência da prole, aceita o inusitado.

Neste sentido, torna-se notório que na atual situação, o pós pandêmico poderá vitimizar muitas pessoas ao redor do mundo, posto que muitos indivíduos estão neste instante passando por situação de desemprego, padecendo num suplício psicológico com o qual jamais puderam lidar e poderão no futuro desenvolver transtornos mentais. (VIEIRA, 2016)

\section{CONSIDERAÇÕES FINAIS}

A situação mundial de emergência evocada pelo alastramento do novo COVID-19 tem intensas reverberações em várias esferas da vida, deste modo a economia no mundo 
tem sido alvo e o mercado global como um todo registra elevadas perdas, se traduzindo nas perspectivas de retração financeira no globo e no fim disto muitos indivíduos têm comprometido a situação, vivendo numa subsistência ante ao desemprego. Por consequência disto, um contingente cada vez mais crescente de indivíduos sofrem precarização da suas vidas e a degradação da autoestima em função da privação do emprego. Por sua vez, os estados têm redescobrindo sua responsabilidade no sentido de induzir a produção e a distribuição de recursos, mas ainda assim não tem dado conta da problemática, por isso o desemprego cresce e a situação de vida se precariza. O sofrimento psicológico, neste contexto, se manifesta em variadas situações às quais chamam a atenção, de modo alarmante, para a questão da saúde mental.

O prognóstico de toda essa crise aponta não só para um período de recessão econômica, mas também para o crescimento do número de indivíduos carentes de atenção psicológica. Nos resta estabelecer estratégias para dar assistência a questão, dando suporte para equacionar a problemática, vendo, ainda que minimamente, oportunidades de produção de sentido e valorização profissional da saúde, chamando ainda a atenção também para maiores investimentos em saúde pública.

$\mathrm{Na}$ prática, o estudo das consequências das crises, nos ajuda a antecipar prognósticos, como a melhoria das políticas públicas de saúde, assistência social e infraestrutura. No que tange a saúde mental as assertivas aqui postas prestam relevante colaboração para a compreensão do momento pelo qual estamos passando, mas principalmente o momento que teremos no porvir.

\section{REFERÊNCIAS}

BBC. Porque o Japão tem uma taxa de suicídios tão alta? [Página da internet]. Disponível em: <https://www.bbc.com/portuguese/noticias/2015/07/150705_japao_suicidio_rb> acesso dia 19 de maio de 2020. 
Estado de Minas internacional. Chega a quase $\mathbf{3 1 2}$ mil o número de mortos pelo coronavírus no mundo. [Página da internet]. Disponível em: <https://www.em.com.br/app/noticia/internacional/2020/05/17/interna_internacional,1 148082/chega-a-quase-312-mil-o-numero-de-mortos-pelo-coronavirus-nomundo.shtml> - Acesso dia 17 de maio de 2020.

MATOS, Daniela. O impacto do desemprego e a saúde psicossocial. Psicologia.pt ISSN 1646-6977. 2018.2 Disponível em: <https://www.psicologia.pt/artigos/textos/A1165.pdf> - acesso dia 17 de maio de 2020.

MENDES, Tatyane. Dia do Trabalho: 5 mudanças da pandemia na vida profissional. [Página da internet]. Disponível em: <https://exame.abril.com.br/carreira/dia-dotrabalho-5-mudancas-do-coronavirus-na-vida-profissional/> - Acesso 17 maio de 2010.

OMS - Organização Mundial da Saúde. Relatório mundial de saúde 2010: financiamento dos sistemas de saúde. 2010. Disponível em: $<$ https://www.who.int/whr/2010/whr10_pt.pdf> - Acesso dia 17 de maio de 2020.

SILVA, Andriele Morais e; LIMA, Súsi Barcelos e. As consequências do desemprego na saúde mental dos trabalhadores desempregados. Anais da $14^{\mathrm{a}}$ Mostra de Iniciação Científica. Urcamp Bagé - RS, 2017.

VIEIRA, Carlos Eduardo Carrusca; SILVA Camila Aparecida; SILVA, Karina Aparecida de Fátima da; ALVES, Mariany Aparecida; MARTINS, Miquéias de Oliveira. Impactos psicossociais do desemprego sobre a saúde mental e subjetividade de trabalhadores de Arcos/MG. Percurso Acadêmico, Belo Horizonte, v. 6, n. 11, jan./jun. 2016. DOI: https://doi.org/10.5752/P.2236-0603.2016v6n11p292-295.

\section{APÊNDICE- REFERÊNCIAS DE NOTA DE RODAPÉ}

2.

https://www.em.com.br/app/noticia/internacional/2020/05/17/interna_internacional,11 
48082/chega-a-quase-312-mil-o-numero-de-mortos-pelo-coronavirus-nomundo.shtml - acesso dia 17 de maio de 2020.

3. https://exame.abril.com.br/carreira/dia-do-trabalho-5-mudancas-do-coronavirus-navida-profissional/

4. Trata-se de benefício em duas quotas no valor de $R \$ 600,00$, minimizando os efeitos da pandemia na economia. Já o BEM funciona em regime semelhante e é destinado aos trabalhadores formais.

Enviado: Maio, 2020

Aprovado: outubro, 2020 